\title{
Challenges in the New Millennium: Product Discovery and Design, Enterprise and Supply Chain Optimization, Global Life Cycle Assessment
}

\author{
Ignacio E. Grossmann \\ Department of Chemical Engineering, Carnegie Mellon University, \\ Pittsburgh, PA 15213, U.S.A.
}

\begin{abstract}
This paper first provides an overview of the financial state of the process industry, major issues it currently faces, and job placement of chemical engineers in the U.S. These facts combined with an expanded role of Process Systems Engineering, are used to argue that to support the "value preservation" and "value growth" industry three major future research challenges need to be addressed: Product Discovery and Design, Enterprise and Supply Chain Optimization, and Global Life Cycle Assessment. We provide a brief review of the progress that has been made in these areas, as well as the supporting methods and tools for tackling these problems. Finally, we provide some concluding remarks.
\end{abstract}

Keywords: Process Systems Engineering, Process and Product Design, Supply Chain Optimization, Life Cycle Analysis.

\section{INTRODUCTION}

When Professors Chen and Westerberg invited me to give a keynote lecture on research challenges in the new millennium at the PSE2003 meeting I was rather hesitant to accept their invitation since I was unsure whether I would be in a position to contribute to such an imposing topic. However, after realizing I did not have to provide a research agenda for the entire next millennium, but at best for the next few years, what also made me decide to accept were three major facts. The first is that the future of Process Systems Engineering (PSE) has been very much in my mind through an AIChE perspectives article that I coauthored with Art Westerberg (Grossmann and Westerberg, 2000), and through my involvement in a committee of the National Research Council, which produced the report "Beyond the Molecular Frontier: Challenges in Chemistry and Chemical Engineering in the $21^{\text {st }}$ Century," (Breslow et al. 2003). Second, having been department Head at Carnegie Mellon for the last eight and one half years, my interactions with employers and advisory boards has given me a useful perspective on the educational and research needs of the chemical industry. Third, I have had the opportunity to be involved in the Council for Chemical Research, and in the AIChE Journal as an associate editor. These activities, as well as the headship at Carnegie Mellon, have helped me to gain a broader appreciation of our profession. Therefore, it is in this context that I would like to take the opportunity to speculate about future research challenges in Process Systems Engineering. 
The paper is organized as follows. We first define the landscape in industry by presenting several financial facts, economic and social challenges, and job placement data in the process industry. Next we discuss the major trends in the industry, as well as the expanding role of Process Systems Engineering. Finally, we discuss the future challenges identifying Product Discovery and Design, Enterprise and Supply Chain Optimization, and Global Life Cycle Assessment as major themes for future research.

\section{LANDSCAPE OF THE PROCESS INDUSTRY}

Since Process Systems Engineering has as a major objective to develop new methods and tools that allow industry to meet its needs by tying science to engineering, it is important to identify the major facts and trends in industry that motivate the challenges for future research in this area.

In this section we consider first several financial facts about the chemical process industry. We then discuss some of the major economic and social issues that are being faced by the industry, and lastly we present some data for placement of chemical engineers. We restrict the data to the U.S. industry for the sake of consistency.

2.1 Financial facts. While it has become trendy over the last few years to question the future of chemical engineering and the process industry, it is important to note that the latter still remains a major sector of the economy. As an example, Chemical Engineering News reported in its June 24 issue of 2002 (pp.44-57) that the total revenues of chemicals in the U.S. in 2001 amounted to $\$ 447$ billion. The breakdown by product types in billions is shown in Table 1. If we expand the process industry by adding the petroleum industry, the revenues reported by major U.S. oil companies in 2001 were $\$ 595$ billion. Thus, between chemicals and petroleum, the total revenue in the U.S. is close to $\$ 1,000$ billion per year.

Table 1. Revenues of chemicals in the U.S. in 2001 (billions)

\begin{tabular}{lc}
\hline Basic chemicals & $\$ 146.8$ \\
Pharmaceuticals & 119.9 \\
Specialty chemicals & 108.6 \\
Consumer products & 48.4 \\
Crop protection & 13.7 \\
Fertilizers & 10.4 \\
\hline
\end{tabular}

Expenditures in capital spending of the top 25 U.S. chemical producers (i.e. basic and specialty chemicals) were $\$ 7.074$ billions in 2001 , which is considerably lower than the $\$ 9.333$ billion in 1998 . The R\&D expenditures were $\$ 4.798$ billions in 2001 versus $\$ 5.023$ in 1998. In contrast, the pharmaceutical industry saw their R\&D expenditures increase from $\$ 15.2$ billion in 1998 to $\$ 20.9$ billion in 2001. It is also interesting to note that in 2001 one in 12 researchers in industry worked for a chemical or pharmaceutical company, while the expenditure of R\&D in the chemical sector was about $10 \%$ among all industrial sectors. 


\begin{tabular}{lc}
\multicolumn{2}{l}{ Table 2. Revenues of major U.S. chemical companies in 2001 (billions) } \\
\hline ExxonMobil & $\$ 191.6$ \\
ChevronTexaco & 99.7 \\
Merck & 47.7 \\
Procter \& Gamble & 39.2 \\
Johnson \& Johnson & 33.0 \\
Pfizer & 32.2 \\
Dow & 27.8 \\
DuPont & 26.8 \\
Bristol-Myers Squibb & 21.7 \\
Amgen & 3.5 \\
Genentech & 1.7 \\
\hline
\end{tabular}

To provide another perspective, the revenues of major companies in the process industry in 2001 are shown in Table 2. From the figures in this table it is clear that the petroleum companies have the largest revenues followed by pharmaceuticals, consumer products and chemical companies. Biotechnology companies are last with relatively small revenues. In terms of profitability and approximate return, however, the order is first biotechnology (20$30 \%)$, then pharmaceutical (15-20\%), petroleum (6-10\%) and finally chemical companies (5$8 \%$ ).

2.2 Economic and social issues. The chemical process industry faces very important economic and social issues (Breslow et al., 2003). Globalization of the industry has opened new markets. While potentially this can help to increase the standard of living throughout the world, globalization has also resulted in growing worldwide competition. Furthermore, the introduction of e-commerce is producing greater market efficiencies, while at the same time greatly reducing the profit margins. Added to these challenges are increased investor demands for predictable earnings growth despite the cyclical behavior inherent in most of the chemical industry, which tends to be capital intensive.

Socially, sustainability and protection of the environment will become even more important challenges for the process industries. Many of the raw materials used, especially those derived from oil, gas, and some plants and animals have been, and in some cases continue to be, depleted at rates either large compared to known reserves, or faster than replenishment. Also, by the very nature of chemistry, there are always contaminants in the raw materials, incompletely converted raw materials, unavoidable byproducts, or spent catalysts and solvents that produce waste. These challenges also apply to the production of the energy from the fuels produced by or consumed by the processing industries. Another concern that has recently received great attention is the potential detrimental effects of carbon dioxide emissions to the atmosphere. Recent estimates indicate that the level of carbon dioxide in the atmosphere has increased by a third since the beginning of the industrial age, and that it currently contributes about $73 \%$ to the potential for global warming. Finally, another concern is the management of water, which is expected to become a major problem in this century.

Almost all chemical manufacturers in the U.S., and increasingly world-wide, now subscribe to a program called Responsible Care, a pledge by the manufacturers to make only products 
that are harmless to the environment and to its living occupants, and by processes that are also environmentally and biologically benign.

Closely related to the environmental challenges are the energy challenges. Currently about $85-90 \%$ of the world's energy is obtained by burning fossil fuels (petroleum, natural gas, and coal), but this will change at some point. Regarding alternative energy sources for the process industry, better ways need to be devised to use solar and wind energy to effectively convert them to electricity. Combustion needs to be eventually replaced by fuel cell technology, and the safe and economic use of hydrogen needs to be made a reality. There are also important future implications for petroleum companies if rechargeable batteries become practical in electric motor vehicles, obviating the need of gasoline engines.

Finally, the industry also has to respond to diseases and poverty, particularly in the developing world. For instance, a major challenge is the development and manufacture of low cost drugs to combat diseases such as AIDS.

2.3 Placement of chemical engineers. Another angle that is important to analyze is the change in the job placement of graduates in chemical engineering, which has been a result of changes in the industry. Twenty years ago most graduating students would join petroleum and chemical companies. Nowadays this has greatly changed. Figs. 1(a) and 1(b), which are a result of a survey conducted by AIChE, show the distribution of jobs offered to graduates with B.S. and Ph.D. degrees in 2001. The data is for about $60 \%$ of the graduating students in each case. At the B.S. level the remaining $40 \%$ works for the government $(2 \%)$, pursues a graduate or professional degree $(12 \%)$, is unemployed $(3.5 \%)$, or their employment status is unknown (20\%). At the Ph.D. level the other $40 \%$ works for the government $(0.8 \%)$, takes on a faculty position $(17 \%)$, does postdoctoral work $(13 \%)$, is unemployed $(2.8 \%)$, or their employment status is unknown $(6 \%)$.

What is striking from Fig. 1 is the diversity of industries that employ chemical engineers. At the B.S. level chemicals, fuels and food/consumer product companies hired almost $50 \%$ of the students. Electronics hired as many as the fuels companies (16\%), while the share of biotechnology and pharmaceutical, and engineering services and consulting, was close to $10 \%$ for each. At the Ph.D. level the trends are similar, although chemicals, fuels and consumer products show a share of only 35\%, which is slightly above electronics at $30 \%$. Also biotechnology and pharmaceuticals has a 16\% share.

To appreciate the significant changes that have taken place over the last ten years in the placement of chemical engineers, the percent changes at the B.S. and Ph.D. levels in the four major sectors is shown in Table 3. There is a striking decrease in chemicals, and increase in electronics. Bio/pharma also shows growth but at half the rate of electronics. The drop in fuels is also noticeable, but not as dramatic as in chemicals. Food and consumer products are fairly constant. 


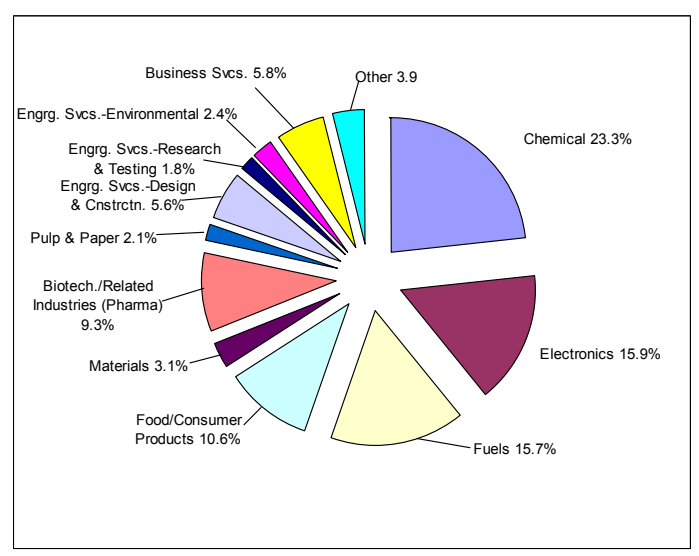

(a)

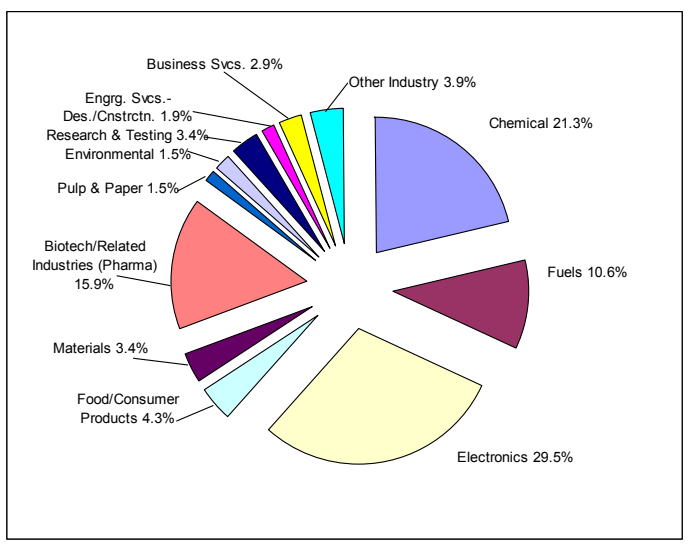

(b)

Fig. 1. Distribution of 2000-01 industry placements of (a) B.S. and (b) Ph.D. graduates in the U.S.

Table 3. Change in percentage placement of graduates in the U.S.

\begin{tabular}{lllll}
\hline & B.S. 91 & B.S. 01 & Ph.D.91 & Ph.D. 01 \\
\hline Chemicals & 43.7 & 23.3 & 46.0 & 21.3 \\
Fuels & 21.2 & 15.7 & 15.3 & 10.6 \\
Food/Consumer Prods. & 7.2 & 10.6 & 5.5 & 4.3 \\
Electronics & 2.4 & 15.9 & 4.8 & 29.5 \\
Bio/Pharma & 3.1 & 9.3 & 4.0 & 15.9 \\
Others & 22.4 & 25.2 & 24.4 & 18.4
\end{tabular}

\section{DISCUSSION OF TRENDS IN INDUSTRY}

The material that we presented in section 2 could be the subject of a separate article. Our intent here is to use these data and issues as a basis to motivate the future research agenda in Process Systems Engineering in terms of three major themes: Product Discovery and Design, Enterprise and Supply Chain Optimization, and Global Life Cycle Assessment.

The data of the previous section clearly show that although the traditional chemical industry (i.e. chemicals, petroleum, consumer products) has greatly shrunk in terms of employment and $R \& D$ expenditures, its revenues are still very large (see Tables 1 and 2). The data also show that the biotechnology and pharmaceutical sector has become of significant importance even though their revenues are one quarter of the total industry in the U.S. (see Table 1). Surprisingly, the electronics sector has become almost as important as the other sectors in terms of employment. In this case, companies such as IBM (revenue $\$ 86$ billion), HP (revenue $\$ 45$ billion), and INTEL (revenue \$27 billion), which are dominated by electrical and computer engineers, have hired chemical engineers largely for their process skills, which are important in chip manufacturing. 
One implication of the above, and of the financial and placement data in section 2 , is that it is important to recognize on the one hand the very large magnitude of the "value preservation" part of the industry (e.g., large-scale commodity chemicals, petroleum), and on the other hand the great potential of the "value growth" part of the industry (e.g., specialty chemicals, biotechnology and pharmaceutical products). Obviously, most companies are in fact dealing with both aspects, particularly since the specialty chemical today becomes the commodity chemical of tomorrow, and this transition seems to be accelerating, even in the case of the pharmaceutical industry.

Therefore, for companies in the process industry to remain competitive and economically viable, this requires for the "value preservation" part of the industry the optimization of the enterprise and its supply chain by reducing costs and inventories, operating efficiently and continuously improving product quality. For the "value growth" part it means innovating and becoming smarter and quicker in product discovery and design, as well as in their commercialization, particularly in reducing the time to market. But the challenges posed by the energy and the environment discussed in section 2.2 must also be urgently addressed, as they are likely to have a profound effect on the long-term viability and acceptance of the chemical industry. It is here where global life cycle assessment will become an essential task that must be undertaken effectively.

\section{EXPANDING THE SCOPE OF PROCESS SYSTEMS ENGINEERING}

Process Systems Engineering has traditionally been concerned with the understanding and development of systematic procedures for the design, control and operation of chemical process systems (Sargent, 1991). However, as discussed in Grossmann and Westerberg (2000), the scope of PSE can be broadened by making use of the concept of the "chemical supply chain" shown in Fig. 2. The supply chain starts at the molecular level with of chemicals that must be discovered or synthesized. Subsequent steps aggregate the molecules into clusters, particles and films as single and multiphase systems that finally take the form of macroscopic mixtures. Through scale-up, we next move to the design and analysis of the production units that must be integrated in a process flowsheet. Finally, that process becomes part of a site with several plants that are connected through suppliers, warehouses and distribution centers, which ultimately defines a commercial enterprise.

Based on Fig. 2, Grossmann and Westerberg (2000) define Process Systems Engineering as the field that is concerned with the improvement of decision making processes for the creation and operation of the chemical supply chain. It deals with the discovery, design, manufacture and distribution of chemical products in the context of many conflicting goals. A major change with this definition of PSE is the move away from process units and plants. In one direction the move is towards the molecular level in order to aid in the discovery and design of new molecular structures. In the other direction, the need is to move towards the enterprise level in order to help the coordination of the logistics for manufacturing and production planning with the entire supply chain. These two trends are consistent with the themes Product Discovery and Design, and Enterprise and Supply Chain Optimization, respectively. Furthermore, since the objective is to ultimately integrate from the R\&D level through the process manufacturing level, and finally to the distribution level, this gives rise 
to the theme of Global Life Cycle Assessment that requires covering all the length and time scales of the subsystems involved in Fig. 2.

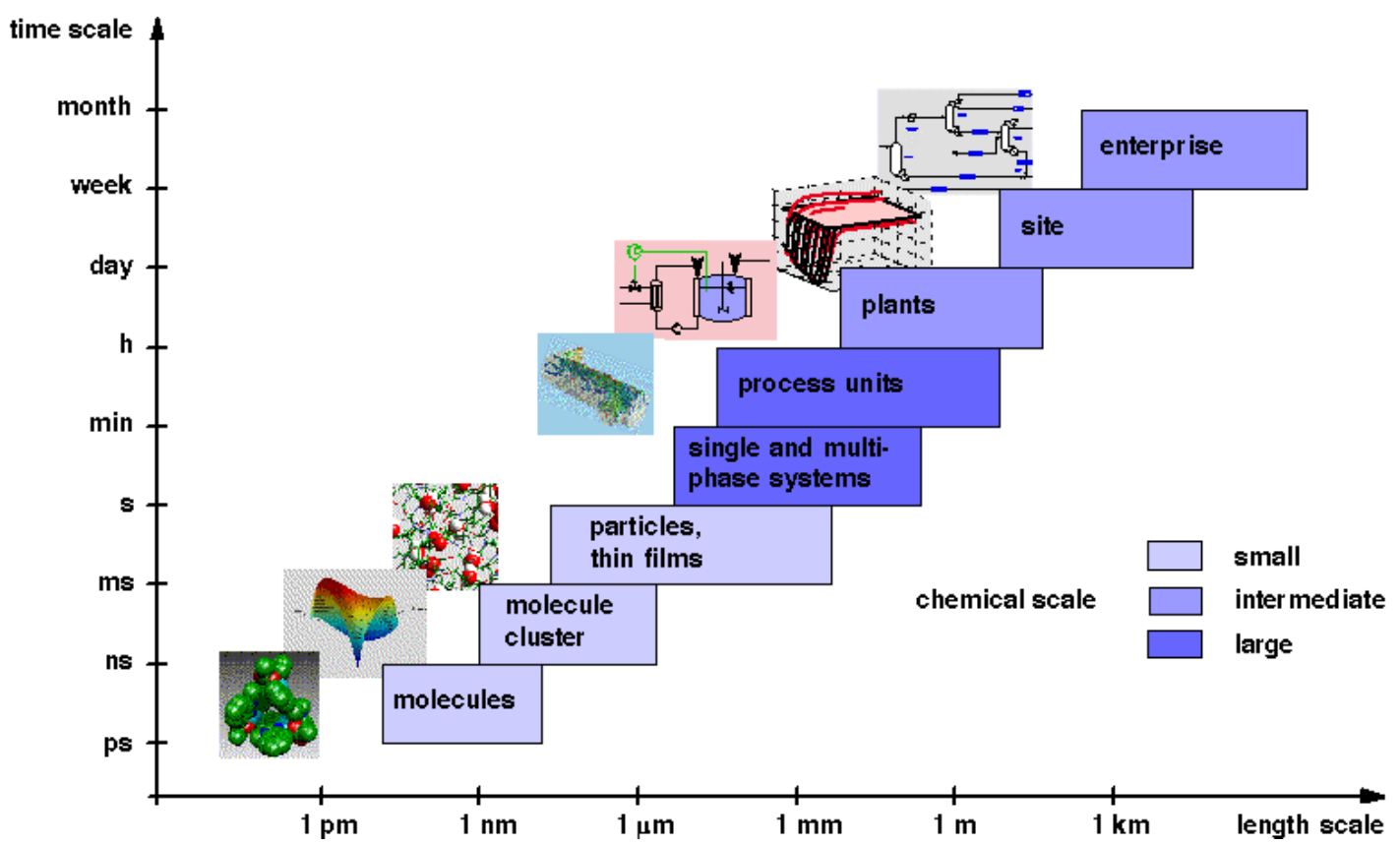

Fig. 2. The "chemical supply" chain"

\section{FUTURE CHALLENGES}

Based on the previous sections, it would appear that Product Discovery and Design, Enterprise and Supply Chain Optimization, and Global Life Cycle Assessment are likely to emerge as major research challenges in the PSE area over the next decade. Methods and tools, traditional strengths of PSE, will also continue to be of central importance. Below we discuss each of these themes.

\subsection{Product Discovery and Design.}

In order to move towards the molecular level, traditional process design is expanding to include molecular product design (Joback and Stephanopoulos, 1989). Promising work in this area, which has been labeled as CAMD (Computer-Aided Molecular Design), has been recently summarized in the book by Achenie et al. (2002). Good progress has been made here in developing optimization models for synthesizing molecular structures of solvents, refrigerants and polymers (e.g. see Pretel et al., 1994; Camarda and Maranas, 1999; Duvedi and Achenie, 1997; Sahinidis and Tawarmalani, 2000). A major challenge that remains is the need to develop more accurate predictive capabilities for properties of compounds in order to apply the optimization methodologies (Sinha et al., 2002). Ideally one would like to resort to molecular simulation models (De Pablo and Escobar, 2002), which are increasingly

\footnotetext{
* This figure is courtesy of Professor Wolfgang Marquardt, RWTH Aachen (Marquardt et al, 2000).
} 
providing very good predictions as for instance shown in the work by Bowen et al. (2002). Closely related to CAMD is the design and analysis of proteins and biological molecules (see Maranas et al, 2003), where predictive properties tend to be probabilistic as they large rely on experimentation. On the other hand, force-field and ab-initio models are being developed for protein structure prediction as reported by Floudas and Klepeis (2001), Klepeis and Floudas (2002) and Westerberg and Floudas (1999), who have made use of global optimization techniques to solve these problems. To support the expansion to R\&D through product discovery, optimal planning and scheduling techniques for new product development are also receiving increased attention to better coordinate the pipeline of new products and their testing in the agrochemical and pharmaceutical industry (e.g. see Blau et al., 2000; Maravelias and Grossmann, 2001; Subramanian et al., 2003; Shah, 2003)

At the macroscopic level, product design is also emerging as an intriguing area of research (Cussler and Moggridge, 2001; Westerberg and Subramanian, 2000), although industry has practiced product design for a long time. The emphasis in research is the tie of new products to market needs, and the systematic exploration of alternatives for developing new products, which normally must be accomplished in multidisciplinary teams that are composed by scientists, engineers of other disciplines and business people. An interesting problem here that has not received enough attention is the integration of product and process design, an example of which is the work by Vaidyraman and Maranas (1999) on synthesis of refrigeration synthesis and refrigerant selection. Also, the design of electronic and optic devices would seem to be a worthwhile area given the number of chemical engineers who are hired by the electronics industry (e.g. see Itle et al., 2002).

Process design will of course still involve significant research challenges. The lack of commercial tools for the synthesis of large-scale commodity flowsheets clearly indicates the need for new developments and approaches (e.g. see Gadewar et al., 2001; Ismail et al., 1999; Shelley and Halwagi, 2000; Wilson and Maniuosiouthakis, 2000; Yeomans and Grossmann, 1999). Also, among the assessment of operability measures safety is the one that still remains a major challenge (e.g. see Huang et al., 2002). The interaction between design and control also continues to attract attention (Bansal et al., 2002; Design and control of batch and biological processes will also become more prominent. Another related challenge is the area of process intensification that requires discovering novel unit operations that integrate several functions and that can potentially reduce the cost and complexity of process systems (Stankiewicz and Moulin, 2000). While significant progress has been made in the area of reactive distillation (e.g. see Nisoli et al. 1997; Lee et al., 2000; Jackson and Grossmann, 2001), there is not yet a systematic procedure for synthesizing more general units, let alone processes, that integrate functions in a novel way.

Other areas that are likely to receive increased attention due to the growth in new industries include synthesis of micro-systems and design of micro-structured materials. An example of the former is work by Pfeiffer et al. (2002) that deals with the synthesis of chip-based electrophoretic systems, while an example of the latter is the work by Winn and Doherty (1998) on crystallization that is of significance in the pharmaceutical industry. Also, biological related processes, starting at the level of the genome (Hatzimaikatis, 2000; Maranas et al., 2003), going through metabolic networks (Stephanopoulos, 2002) and finally 
to process units and flowsheets (Lee et al. 1997; Steffens et al, 2000) will give rise to design and control problems that are likely to attract attention, and lead to problems that have not been investigated previously (e.g. synthesis of separation of very dilute systems). Finally, biomedical applications such as drug delivery (Parker and Doyle, 2001), and anesthesia (Morari and Gentilini, 2001), provide new opportunities for applications of process control methodologies. Surprisingly, there are only very few applications in the electronics area (Edgar et al., 2000), despite the fact that this sector hires a large number of chemical engineers as was seen in section 2.3.

\subsection{Enterprise and Supply Chain Optimization.}

This area is attracting a great deal of attention from industry and academia, as was shown in the recent FOCAPO2003 meeting in Coral Springs. While the applications are aimed mostly at commodities, there are also increasingly applications in specialties, pharmaceuticals (Shah, 2003), and in the food industry (Masini et al, 2003). Major challenges in this area include development of models for strategic and tactical planning for process networks (Shapiro, 2003) that often require the solution of large-scale multiperiod optimization problems. Furthermore, these models must be eventually integrated with scheduling models. While very significant progress has been made, these models still lack sufficient generality despite significant advances made in this area (e.g. Bassett et al, 1997; Kondili et al., 1993; Pantelides, 1994; Ierapetritou and Floudas, 1998; Maravelias and Grossmann., 2003a). Also, the efficient solution of these models and extension to rescheduling (Mendez and Cerda, 2003) is required for their application to real-time scheduling and their handling of uncertainties (e.g. Honkomp et al., 1997; Balasubramanian and Grossmann, 2002). The incorporation of cash flows and related financial issues in planning and scheduling has been addressed by Badell and Puigjaner (2001) and Romero at al. (2003. The incorporation of uncertainty in planning and scheduling models through stochastic optimization still remains a great challenge due to the very large computational requirements that are needed (Sahinidis, 2003). However, this is clearly an area that might be ripe for significant progress, including ways for better quantifying financial risk (e.g. see Barbaro and Bagajewicz, 2004). Another interesting challenge is the characterization of dynamics in supply chains and the application of control methodologies in order to improve responsiveness (Vargas-Villamil and Rivera, 2000; Perea et al, 2001; Nishi et al., 2002). Interestingly the work by VargasVillamil and Rivera deals with semi-conductor manufacturing.

In order to fully address the enterprise and supply chain optimization requires a tighter integration with the operation at the plant level. Here the areas of data reconciliation and sensor location still offer interesting challenges for optimization (see Bagajewicz, 2003; Chmieliwski et al., 2002), while the areas of verification, abnormal events management, and synthesis of operating procedures (Barton and Lee, 2003; Venkatsubramanian, 2003) are being approached by knowledge-based systems, and increasingly with emerging methods for hybrid systems (Silva et al., 2001). The development of effective plant-wide model predictive control is also very relevant in order to provide a seamless integration of the plant with the planning and supply chain optimization models. The major pending research problem that still remains is the integration of planning, scheduling and control, whether at the plant level, or at the supply chain level. Major difficulty is ensuring consistency, feasibility and optimality across models that are applied over large changes in times scales 
(years, months, down to days and seconds). Another outstanding problem is the design of supply chains in the face of restructuring in the industry.

\subsection{Global Life Cycle Assessment.}

Supporting the goal of Responsible Care by the chemical industry will require development of systematic methods and tools for design of environmentally benign products and processes. At the process level significant progress has been made in the synthesis and optimization of water networks (for a review see Bagajewicz, 2000). Progress has also been made to better understand the implications of waste at the level of the synthesis and analysis of a process flowsheet (e.g. Pistikopoulos et al., 1994; El-Halwagi, 1997; Cano-Ruiz and McRae, 1998; Cabezas et al., 1999; Linninger and Chakraborty, 2001; Sikdar and ElHalwagi, 2001). Little work, however, has been made to assess environmental implications at the level of product design, and the integration with processing. Examples have been the work by Sinha et al. (1999) for design of environmentally benign solvents, and the work by Hostrup et al. (1999) for design of solvents and synthesis of separation systems. More importantly, however, is the need to adopt broader approaches to the Life Cycle Assessment of Products and Processes in order to predict more accurately their long-term sustainability (Heijungs et al., 1996; Korevaar, 2000; Nebel and Wright, 2002). While few interesting measures have been proposed to support this assessment in the PSE community in terms of thermodynamics (Bakshi, 2000) and in terms of IT to document all the elements involved in the life cycle of a plant design (Schneider and Marquardt, 2002), an open question is still what are good measures for sustainability. Also more comprehensive approaches to sustainability are required as has been done in other disciplines (e.g. Hendrickson et al., 1998). An interesting related question is how to effectively recycle excess products by using a "reverse supply chain" (Biehl et al., 2002). Also, the consideration of atmospheric chemistry and global climate change (Seinfeld and Pandis, 1997; Seinfeld, 2000) should be incorporated to provide a truly global assessment. Furthermore, this would also provide a stronger basis for investigating the carbon sequestration problem (Johnson and Keith, 2001).

\subsection{PSE Methods and Tools.}

A comprehensive approach to Product Discovery and Design, Enterprise and Supply Chain Optimization, and Global Life Cycle Assessment will involve the solution of a number of challenging problems, including the integration of several parts of the chemical supply chain in Fig. 2. This will require the multi-scale modeling ranging from the atomic level to the enterprise level, as well as the development and improvement of supporting methods for simulation, optimization, control and information processing.

While significant progress has been made in optimization in areas such as nonlinear and mixed-integer optimization (Biegler and Grossmann, 2002) there are still many outstanding problems (Grossmann and Biegler, 2002). The solution of very large-scale differentialalgebraic methods whether for dynamic simulation and real-time optimization of entire plants involving millions of variables, or for simulating systems at multiple scales (e.g. fluid mechanics and molecular dynamics) is a capability that is still at relatively early stages (Biegler et al, 2002). There is also need for methods for simulating and optimizing under uncertainty, a capability that is still limited to fairly small problems due to the great potential computational expense (Sahinidis, 2003). Related capabilities where good progress has been 
made are new approaches to flexibility analysis (Ierapetritou, 2001; Novak and Kravanja, 1999) and parametric programming (Dua and Pistikopoulos, 1999), although current methods are still restricted to relatively small problems. Another important capability will be advanced optimization tools that can handle mixed-integer, discrete-logic and quantitativequalitative equations to model synthesis and planning and scheduling problems more effectively (Grossmann et al., 2002; Grossmann, 2002). Generalized Disjunctive Programming (Lee and Grossmann, 2003) and Constraint Programming (Hooker, 2000) are novel approaches that offer alternative solution methods, with the former appearing to be especially useful for synthesis problems, and the latter on scheduling problems. An interesting problem here is the development of hybrid methods that effectively combine these techniques (Jain and Grossmann, 2001; Maravelias and Grossmann, 2003b). Another very important problem that is still in its infancy is mixed-integer dynamic optimization (Bansal et al., 2001). Global optimization has also seen significant progress for solving problems with a specific structure (Adjiman et al., 1998a, 1998b; Ryoo and Sahinidis, 1996; Sahinidis, 1996). Nevertheless, there is still a need to effectively address the solution of large-scale problems, problems involving arbitrary functions, equations (Lucia, 2002) and problems involving differential equations (Papamichail and Adjiman, 2002). A very different approach that is being explored for the approximate global optimization is agent-based computations (Siirola et al, 2002), which has been motivated by the area of complex systems (Ottino, 2003) and that has been recently applied to supply chain problems (Julka et al., 2002)

In the area of process control vigorous efforts continue in the areas of model predictive control (Rawlings, 2000; Morari et al., 2003), which is being increasingly applied to new systems such as simulated moving bed chromatography system (Natarajan and Lee (2000). Other efforts include system identification (Jorgensen. and Lee, 2002), process monitoring (Kourti and MacGregor, 1996), and fault diagnosis (Zhao et al., 1998; Chiang et al., 2001). Intriguing problems that merit further research is the use of passivity theory (Hangos et al., 1999; Ydstie and Alonso, 1997) for providing a stronger physical foundation to process control, and network theory for structured modeling in control (Mangold et al. 2002). A new interesting development in process control has been the consideration of PDE models (Baker and Christofides, 1999; Christofides, 2001) that in principle will allow tackling dynamic problems at a much greater level of detail, although the computational challenges are formidable. Another very interesting development has been hybrid dynamic systems that involve discrete and continuous variables (Avraam et al, 1998; Benmporad and Morari, 2001; Kowalewski, 2002; Morari, 2002), and that provide a framework for integrating regulatory control with higher level supervisory control functions. A challenging development in hybrid systems has been the incorporation of global optimization methods (Barton and Lee, 2003). Finally, the integration of measurements, control and information systems will emerge as a problem of increased importance with advances in IT (Ydstie, 2002).

Modeling for simulation and optimization will continue to be a major focus of PSE research. New directions include greater integration of traditional algebraic or DAE flowsheet models with PDE models for Computational Fluid Dynamics calculations (Oh and Pantelides, 1996), integration of macroscopic models with molecular simulation models (Stefanović and 
Pantelides, 2000) in order to support multi-scale computations. Also, modeling tools are needed for the natural specification of logic and discrete decisions (Vecchietti and Grossmann, 2000) as well as for accommodating hierarchical decisions such as in conceptual design (Douglas, 1985). Information modeling tools (Davis et al., 2001; Eggersmann et al., 2002), will also become increasingly important for supporting integration problems, and for problem solving by large and globally distributed teams (Eggersmann et al., 2003).

Advances in computing, both in performance growth of computing hardware and in object oriented software development will help to realize some of the supporting tools described above. Higher number of cycles and larger memories can be expected in the future, which will help in addressing a number of the larger problems described above (e.g. Mallya et al., 1999 , for process simulation). The need for advanced computing has led to the development of cheap, high performance clusters, such as the Beowulf class computers (e.g. see http://beowulf.cheme.cmu.edu). These have leveraged the availability cost effective components (microprocessors, motherboards, disks and network interface cards) and publicly available, hardware independent software. Beowulf clusters allow the possibility of large-scale parallel computing for the price of standard components. Finally, wireless computing may also create new needs for effectively supporting team work by diverse and distributed specialists .

\section{CONCLUDING REMARKS}

The financial trends, issues and changes in job placement, and the broadening of PSE, would indicate that in order to support "value preservation" and "value growth" in the process industry will require new advances and developments from PSE in three major areas: Product Discovery and Design, Enterprise and Supply Chain Optimization, and Global Life Cycle Assessment. Furthermore, to make progress in these areas continued work is required in basic PSE methods and tools. While this is not a surprising conclusion, we can make a few remarks and observations based on the data and review of recent work that we presented:

1. While a shift to product design is a welcome change in PSE to support "value growth," it should not be separated from process design, which is a core capability of chemical engineers and PSE. Furthermore, to support discovery it is paramount to connect the molecular level design with properties at the macroscopic level.

2. The area of enterprise and supply chain optimization offers a unique opportunity to PSE given its potential to impact the "value preservation" part of the industry, which is under great competition. Supply chain optimization of course offers opportunities in the "value growth" industry such as in pharmaceuticals.

3. Despite the great importance of sustainability and environmental issues, the research efforts from the PSE community have been rather timid. A bolder and more creative approach is clearly needed. One intriguing opportunity might be process intensification as a way to revolutionize chemical plants. Another opportunity could be stronger interaction between product and process design as part of a life cycle analysis of chemicals. 
4. There are many potential and exciting possibilities in biological related research in PSE. However, industrial growth in that area is unlikely to become sufficiently large so that it should become the major focus of PSE research.

5. The electronics area has received be little attention by the PSE community despite the significant number of chemical engineers who have been hired by that industry. PSE should be able to contribute to the simulation and optimization of chip manufacturing processes, as well as in the area of product design by exploiting our knowledge of chemistry and chemical engineering.

6. Since many of the computational challenges of PSE tools arise with large problem sizes, there might be the temptation to think that faster and more advanced computers is all that is needed. While these developments will obviously have significant impact, the breakthroughs will come with synergy of new theories and algorithms as it has happened in the case of LP and MILP optimization (Bixby, 2002).

Finally, we hope that this paper has shown that in PSE there are many problems that are intellectually challenging and that are relevant to industry. The important goal is to make sure that new research directions in the "new millennium" emphasize both points.

ACKNOWLEGDMENTS. The author gratefully acknowledges the Flulbright Commission in Spain for financial support for a Senior Lectureship at the University of Cantabria in Santander. Many thanks to Christos Maravelias, Conor McDonald and Stratos Pistikopoulos for their useful comments and feedback on this paper.

\section{REFERENCES}

Achenie, L.E.K., R. Gani and V. Venkatasubramanian (Editors), "Computer Aided Molecular Design: Theory and Practice," Elsevier Publishers (2002)

Adjiman, C.S., S. Dallwig, C.A. Floudas, and A. Neumaier, "A Global Optimization Method, $\alpha$ BB, for General Twice-Differentiable Constrained NLPs - I. Theoretical Advances", Computers and Chemical Engineering, 22, pp. 1137-1158 (1998a).

Adjiman, C.S., I.P. Androulakis, and C.A. Floudas, "A Global Optimization Method, $\alpha$ BB, for General TwiceDifferentiable Constrained NLPs - II. Implementation and Computational Results", Computers and Chemical Engineering, 22, pp. 1159-1179 (1998b).

Avraam, M. P., N. Shah, and C. C. Pantelides, "Modelling and Optimisation of General Hybrid Systems in the Continuous Time Domain," Computers and Chemical Engineering, 22, Suppl., S221-S228 (1998).

Badell, M. and L.A. Puigjaner, "Advanced enterprise resource management systems for the batch industry. The TicTacToe algorithm,” Computers \& Chemical Engineering 25, 517-538 ( 2001).

Bagajewicz, M., "A Review of Recent Design Procedures for Water Networks in Refineries and Process Plants," Computers and Chemical Engineering, 24, 2093-2114 (2000).

Bagajewicz, M., "Data Reconciliation and Instrumentation Upgarde. Overview and Challenges," Proceedings FOCAPO 2003 (Eds. I.E. Grossmann and C.M. McDonald), pp.103-116, CACHE (2003). 
Baker, J. and P. D. Christofides, "Output Feedback Control of Parabolic PDE Systems with Nonlinear Spatial Differential Operators," Ind. \& Eng. Chem. Res., 38, 4372-4380, 1999.

Bakshi, B.R. "A thermodynamic framework for ecologically conscious process systems engineering," Computers and Chemical Engineering, 24, 1767-1773 (2000).

Balasubramanian, J. and I.E. Grossmann, "Scheduling to Minimize Expected Completion Time in Flowshop Plants with Uncertain Processing Times," Computers and Chemical Engineering 26, 41-57(2002).

Bansal, V., V. Sakizlis, R. Ross, J. D. Perkins, E. N. Pistikopoulos, "New Algorithms for Mixed-Integer Dynamic Optimisation," Report Centre for Process Systems Engineering, Imperial College, London (2001).

Bansal, V.; Perkins, J. D. and Pistikopoulos, E. N., "A Case Study In Simultaneous Design and Control Using Rigorous, Mixed-Integer Dynamic Optimization Models," Industrial \& Engineering Chemistry Research 41, 760-778 (2002).

Barbaro A. F. and M. Bagajewicz, "Managing Financial Risk in Planning under Uncertainty, " to appear in AIChE Journal (2004).

Barton, P. and C.K. Lee, "Design of Process Operations using Hybrid Dynamic Optimization," Proceedings FOCAPO 2003 (Eds. I.E. Grossmann and C.M. McDonald), pp. 89-102, CACHE (2003).

Bassett, M.H., J. F. Pekny and G. V. Reklaitis, "Using Detailed Scheduling to Obtain Realistic Operating Policies for a Batch Processing Facility", Ind. Eng. Chem. Res., 36, 1717-1726 (1997).

Bemporad A. and M. Morari Optimization-based hybrid control tools Proc. of the 2001 American Control Conference, Arlington (VA), US, Vol. 2, pp. 1689-1703 (2001)

Biegler, L. T., Cervantes A. and Waechter, A. "Advances in Simultaneous Strategies for Dynamic Process Optimization," Chemical Engineering Science, 57, pp. 575-593 (2002).

Biegler, L.T. and Ignacio E. Grossmann, "Retrospective on Optimization," Computers and Chemical Engineering, submitted (2002).

Biehl, M., E. Prater, and M. Realff, "Modeling and Simulation of a Reverse Supply Chain in an Uncertain Environment," INFORMS, San Jose, 2002.

Bixby, R.E., "Solving Real World Linear Programs: A Decade and more of Progress," Operations Research, 50, pp. 3-15 (2002).

Blau, G., B. Mehta, S. Bose, J. Pekny, G. Sinclair, K. Keunker and P. Bunch, "Risk Management in the Development of New Products in Highly Regulated Industries," Computers and Chemical Engineering, 24, pp.659-664 (2000).

Bowen, T.C., J. L. Falconer, R. D. Noble, A. I. Skoulidas, and D.S. Sholl, "Comparison of Atomistic Simulations and Experimental Measurements of Light Gas Permeation Through Zeolite Membranes," Industrial and Engineering Chemistry Research, 41, 1641-1650 (2002).

Breslow, R., M.V. Tirrell, J.K. Barton, M.A. Barteau, C.R. Bertozzi, R.A. Brown, A.P. Gast, I.E. Grossmann, J.M. Meyer, R.W. Murray, P.J. Reider, W.R. Roush, M.L. Shuler, J.J. Siirola, G.M. Whitesides, P.G. Wolnyes and R.N. Zare, "Beyond the Molecular Frontier: Challenges for Chemistry and Chemical Engineering," National Research Academies Press, Washington (2003). 
Cabezas, H., Bare, J. C., \& Mallick, S. K., "Pollution prevention with chemical process simulators: the generalized waste reduction (WAR) algorithm-full version. Computers \& Chemical Engineering, 23, 623 (1999).

Camarda, K.V. and C.D. Maranas, "Optimization in Polymer Design using Connectivity Indices," Industrial \& Engineering Chemistry Research 38, 1884-1892 (1999).

Cano-Ruiz, J. A., and McRae, G. J., “Environmentally conscious process design,”Annual Review on Energy Environment, 23, 499 (1998).

Chiang, L. H., E. L. Russell, and R. D. Braatz. Fault detection and diagnosis in industrial systems. SpringerVerlag, London (2001).

Chmielewski, D. J., T. Palmer, V. Manousiouthakis, “On the Theory of Optimal Sensor Placement,” AIChE J., 48 (5), 1001-1012 (2002).

Christofides, P. D., "Control of Nonlinear Distributed Process Systems: Recent Developments and Challenges," AIChE J., 47, 514-518, 2001

Cussler, E.L. and G. D. Moggridge, Chemical Product Design, Cambridge University Press (2001).

Davis, J.G., E. Subrahmanian, S.L.Konda, H. Granger, M. Collins, A.W. Westerberg, "Creating Shared information Spaces for Collaborative Engineering Design,” Information Systems Frontier, 3(3), 377-392 (2001).

De Pablo, Juan J. and F. A. Escobedo, "Molecular Simulations in Chemical Engineering: Present and Future," AIChE J., 48, pp. 2716-2721 (2002)

Douglas, J.M., "A Hierarchical Decision Procedure for Process Synthesis," AIChE J., 31, 353-362 (1985).

Dua, V. and E.N. Pistikopoulos, "Algorithms for the Solution of Multi-Parametric Mixed-Integer Non-Linear Optimization Problems", Ind. Eng. Chem. Res., 38, 3976-3987 (1999).

Duvedi, A. P. and Achenie, L. E. K., "On the Design of Environmentally Benign Refrigerant Mixtures: A Mathematical Programming Approach," Computers \& Chemical Engineering, 21, 8, 915-923, 1997

Edgar, T.F., S. Butler, W.J. Campbell, C. Pfeiffer, C. Bode, S.B. Hwang, K.S. Balakrishnan and J. Hahn. Automatic Control in Microelectronics Manufacturing: Practices, Challenges, and Possibilities. Automatica Vol. 36(11): pp. 1567-1603, 2000.

Eggersmann, M., R. Schneider and W. Marquardt, "Modeling Work Processes in Chemical Engineering - From Recording to Supporting, “, European Symposium on Computer Aided Process Engineering - 12, (Eds. Grievink, J. v. Schijndel), Elsevier, 871-876 (2002).

Eggersmann, M., S. Gonnet, G.P. Henning, C. Krobb, H.P. Leone, W. Marquardt, "Modeling and Understanding Different Types of Process Design Activities," Lat. Am. Appl. Res. 33, pp.167-175 (2003).

El-Halwagi, M. M., "Pollution Prevention through Process Integration: Systematic Design Tools," Academic Press, 1997.

Floudas, C.A. and J.L. Kleipis, "Deterministic Global Optimization for Protein Structure Prediction" Book in Honor of C. Caratheodory, N. Hadjisavvas and P.M. Pardalos, eds., 31, 2001.

Gadewar, S. B., Doherty, M. F. And Malone, M. F. , "A Systematic Method for Reaction Invariants and Mole Balances for Complex Chemistries," Computers Chem. Engng., 25, 1199-1217 (2001). 
Grossmann, I.E., "Review of Nonlinear Mixed-Integer and Disjunctive Programming Techniques for Process Systems, Engineering," Optimization and Engineering, 3, 227-252 (2002).

Grossmann, I.E. and L.T. Biegler, "Future Perspective on Optimization, " Computers and Chemical Engineering, submitted (2002).

Grossmann, I.E., S.A. van den Heever and I. Harjunkoski, "Discrete Optimization Methods and their Role in the Integration of Planning and Scheduling," AIChE Sympsium Series No. 326, Vol. 98, pp.150-168 (2002)

Grossmann, I.E. and A.W. Westerberg, "Research Challenges in Process Systems Engineering," AIChE J. 46, pp.1700-1703 (2000).

Hangos, K., A. A. Alonso, J. P. Perkins and B. E. Ydstie, "Structural Stability of Process Systems using Thermodynamics and Passivity Analysis", AIChE Journal, Vol 45, pp 802-816 (1999).

Hatzimaikatis, V., "Bioinformatics and Functional Genomics: Challenges and Opportunities," AIChE J., 46, pp. 2340-2343 (2000)

Heijungs, R., G. Huppes, H. Udo de Haes., N. Van den Berg and C.E. Dulith, "Life Cycle Assessment," Paris, France UNEP (1996).

Hendrickson, C.T., A. Horvath, S. Joshi and L. B. Lave, "Economic Input-Output Models for Environmental Life Cycle Assessment," Environmental Science \& Technology, pp. 184A-191A, (1998).

Honkomp, S.J., L. Mockus and G. V. Reklaitis. "Robust scheduling with Processing time uncertainty," Computers Chemical Engineering, Vol 21, pp. 1055-1060 (1997).

Hooker, J., "Logic-Based Methods for Optimization: Combining Optimization and Constraint Satisfaction," John Wiley \& Sons (2000).

Hostrup, M., P.M. Harper and R. Gani, "Design of Environmentally Benign Processes: Integration of Solvent Design and Separation Process Synthesis," Computers and Chemical Engineering, 23, 1395-1414 (1999).

Huang, H., C.S. Adjiman and N. Shah, "A Quantitative Framework for Reliable Safety Analysis", AIChE Journal, 48, 78-96 (2002)

Ierapetritou M.G., "A New Approach for Quantifying Process Feasibility: Convex and one Dimensional QuasiConvex Regions," AIChE J., 47, 1407, 2001.

Ierapetritou M.G. and C.A. Floudas, "Effective Continuous-Time Formulation for Short-Term Scheduling. 1. Multipurpose Batch Processes", Industrial and Engineering Chemistry Research, 37, pp.4341-4359, (1998).

Ismail, S.R., E.N. Pistikopoulos and K.P. Papalexandri "Modular Representation Synthesis Framework for Homogenous Azeotropic Separation", AIChE Journal, 45, 1701-1720 (1999).

Itle, G.C., A.G. Salinger, R.P. Pawlowski, J.N. Shadid, and L.T. Biegler, "A Tailored Optimization Strategy for PDE-Based Design: Application to a CVD Reactor", submitted for publication (2002).

Jackson, J. and I.E. Grossmann, "A Disjunctive Programming Approach for the Optimal Design of Reactive Distillation Columns," Computers and Chemical Engineering 25, 1661-1673 (2001). 
Jain, V. and Grossmann, I.E. "Algorithms for Hybrid MILP/CP Models for a Class of Optimization Problems," INFORMS Journal of Computing, 13, 258-276 (2001).

Joback, K.G. and G. Stephanopoulos, "Designing Molecules Possessing desirded Physical Property Values," Proceedings FOCAPD (Eds. J.J. Siirola, I. Grossmann and Geo. Stephanopoulos), CACHE, Elsevier (1989).

Johnson, T.L. and D.W. Keith, "Electricity from Fossil Fuels Without CO2 Emissions: Assessing the Costs of Carbon Dioxide Capture and Sequestration in US Electricity Markets," Journal of the Air \& Waste Management Association, 51, pp. 1452-1459 (2001).

Jorgensen, S. B. and J. H. Lee, "Recent Advances and Challenges in Process Identification," AIChE Sympsium Series No. 326, Vol. 98, pp.55-74 (2002)

Julka, N., I. Karimi and R. Srinivasan, “Agent-Based Refinery Supply Chain Management,” ESCAPE-12, The Hague (2002)

Klepeis J.L. and C.A. Floudas, "Ab Initio Prediction of Helical Segments in Polypeptides", Journal of Computational Chemistry, 23, 1-22 (2002).

Kondili, E., C.C. Pantelides, and R.W.H. Sargent, "A General Algorithm for Short-Term Scheduling of Batch Operations - I. MILP Formulation. Comput. Chem. Eng. 17, 211-227 (1993).

Kowalewski, S., "Hybrid Systems in Process Control: Challenges, Methods and Limits," AIChE Sympsium Series No. 326, Vol. 98, pp.121-135 (2002)

Kourti, T. and J.F. MacGregor, "Multivariate Statistical Process Control Methods for Monitoring and Diagnosing Process and Product Performance", J. Qual. Tech., 28, 409-428 (1996).

Korevaar, G., 'Sustainable Criteria for Conceptual Process Design', 21st Annual European AIChE Colloquium, The Hague, April 20, 2000

Lasschuit, W. and N. Thijssen, "Supporting Supply Chain Planning And Scheduling Decisions in the Oil and Chemical Industry," Proceedings FOCAPO 2003 (Eds. I.E. Grossmann and C.M. McDonald), pp.37-44, CACHE (2003).

Lucia, A. and Y. Feng, “Global Terrain Methods”, Computers \& Chem. Engineering, 26, 529 (2002).

Lee, J.W., S. Hauan and A.W. Westerberg, "Graphical Methods for Reaction Distribution in a Reactive Distillation Column," AIChE J., Vol. 46(6), 1218-1233, June (2000).

Lee, J., S.Y. Lee and S. Park, "Fed-batch Culture of Escherichia coli W by Exponential Feeding of Sucrose as a Carbon Source", Biotechnology Techniques, 11, pp. 59-62 (1997).

Lee, S. and I.E. Grossmann, "Logic-based Modeling and Solution of Nonlinear Discrete/Continuouis Optimization Problems," to appear in Annals of Operations Research (Eds. M. Guignard-Spielberg and K. Spielberg) (2003).

Linninger, A. A. and Chakraborty, A. "Pharmaceutical Waste Management under Uncertainty", Comp. Chem. Eng., 25, 675-681 (2001).

Mallya, J.U., S.E. Zitney, S. Choudhary and M. A. Stadtherr, "Matrix Reordering Effects on a Parallel Frontal Solver for Large Scale Process Simulation," Computers and Chemical Engineering 23, pp.585-593 (1999). 
Mangold, M., S. Motz, and E.D. Gilles, "A network theory for the structured modelling of chemical processes," Chemical Engineering Science, 57,19, pp. 4099 - 4116 (2002)

Maranas, C.D., G.L. Moore, A.P. Burgard, and A. Gupta (2002), "Systems Engineering Challenges And Opportunities In Computational Biology," Proceedings FOCAPO 2003 (Eds. I.E. Grossmann and C.M. McDonald), pp.13-26, CACHE (2003).

Maravelias, C.T. and I.E. Grossmann, "Simultaneous Planning for New Product Development and Batch Manufacturing Facilities," I\&EC Research 40, 6147-6164 (2001).

Maravelias, C.T. and I.E. Grossmann, "A New General Continuous-Time State Task Network Formulation for Short Term, Scheduling of Multipurpose Batch Plants," I\&EC Research, 42, 3056-3074(2003a).

Maravelias, C.T. and I. E. Grossmann, "A Hybrid MILP/CP Decomposition Approach for the Continuous Time Scheduling of Multipurpose Batch Plants," submitted for publication (2003b).

Masini, G., N. Petracci and A. Bandoni, "Supply Chain Optimization in the Fruit Industry," Proceedings FOCAPO 2003 (Eds. I.E. Grossmann and C.M. McDonald), pp.237-240, CACHE (2003).

Mendez, C. and J. Cerda, "An MILP Framework for Reactive Scheduling of Resource-Constrained Multistage Batch Facilities,” Proceedings FOCAPO 2003 (Eds. I.E. Grossmann and C.M. McDonald), pp.335-338, CACHE (2003).

Marquardt, W., L. v. Wedel, and B. Bayer, "Perspectives on Lifecycle Process Modeling, "(Eds. M.F. Malone, J.A. Trainham, B. Carnahan), AIChE Symp. Ser. 323, Vol. 96, 192-214 (2000).

Morari, M., "Hybrid System Analysis and Control via Mixed Integer Optimization, " AIChE Symposium Series No. 326, Vol. 98, pp.136-149 (2002)

Morari, M. and A. Gentilini A., "Challenges and Opportunities in Process Control: Biomedical Processes," AIChE J., 47, 2140 (2001).

Morari, M., J. H. Lee, C. E. Garcia and D. M. Prett, Model Predictive Control, to be published by Prentice Hall, 2003.

Natarajan, S. and J. H. Lee, "Repetitive Model Predictive Control Applied to a Simulated Moving Bed Chromatography System," Computers and Chemical Engineering, 24, pp. 1127-1133, 2000.

Nebel, B.J. and R. T. Wright, "Environmental Science: Toward A Sustainable Future," Prentice-Hall (2002).

Neiro, S.M.S. and J.M. Pinto, "Supply Chain Optimization of Petroleum Refinery Complexes," Proceedings FOCAPO 2003 (Eds. I.E. Grossmann and C.M. McDonald), pp.59-72, CACHE (2003).

Nishi, T., Masami Konishi, Shinji Hasebe, and Iori Hashimoto, "Autonomous Decentralized Supply Chain Optimization System for Multi-stage Production Processes", Proceedings of 2002 Japan-USA Symposium on Flexible Automation, pp. 131-138 (2002).

Nisoli, A., Malone, M.F., And Doherty, M.F., "Attainable Regions for Reaction with Separation", AIChE Journal, 43, 374-387 (1997).

Novak, Z. and Z. Kravanja, "Mixed-Integer Nonlinear Programming Problem Process Synthesis under Uncertainty by Reduced Dimensional Stochastic Optimization," Ind. Eng. Chem. Res., 38, pp $2680-2698$ (1999). 
Oh, M. and C. C. Pantelides, "A Modelling and Simulation Language for Combined Lumped and Distributed Parameter Systems", Comp. Chem. Engng., 20, 611-633 (1996)

Ottino, J.M., "Complex Systems," AIChE J., 49, 292-299 (2003).

Pantelides, C.C., "Unified Frameworks for the Optimal Process Planning and Scheduling," Proceedings $2^{\text {nd }}$ Conference FOCAPO (Eds. D.W.T Rippin and J. Hale), pp.253-274 (1994).

Papamichail,I., C.S. Adjiman, "A Rigorous Global Optimization Algorithm with Ordinary Differential Equations," Journal of Global Optimization, 24, 1-33 (2002).

Parker, R.S. and F.J. Doyle III, "Control-relevant Modeling in Drug Delivery", Adv. Drug Delivery Reviews, 48, 211-228, (2001).

Perea, E., I.E. Grossmann, E. Ydstie and T. Tahmassebi, "Dynamic Modeling and Decentralized Control of Supply Chains," I\&EC Res. 40, 3369-3383 (2001).

Pfeiffer,A.J., T. Mukherjee and S. Hauan, “Topology trade-offs in the synthesis of chip-based electrophoretic separation systems. Proceedings of MSM '03, pp 250-253. Presented at NanoTech 2003, February 2003, San Francisco CA (USA).

Pistikopoulos, E. N., Stefanis, S. K., \& Livingston, A. G." A Methodology for Minimum Environmental Impact Analysis," AICHE Symposium Series, 90, 139 (1994).

Pretel, E.J., P.A. Lopez, S.B. Bottini and E.A. Brignole, "Computer-Aided Molecular Design of Solvents for Separation Processes," AIChE J., 40, 1349-1360 (1994).

Rawlings, J.B., "Tutorial overview of model predictive control," IEEE Control Systems Magazine, 20(3):38-52, June (2000).

Romero, J., M. Badell, M. Bagajewicz, and L. Puigjaner, "Integrating Budgeting Models into Scheduling and Planning Models for the Chemical Batch Industry,” Ind. Eng. Chem. Res., 42 (24), 6125 -6134 (2003).

Ryoo, H. S. and N. V. Sahinidis. A branch-and-reduce approach to global optimization. Journal of Global Optimization 8(2):107-139 (1996).

Sahinidis, N.V., "Optimization under Uncertainty: State of the Art and Opportunities," Proceedings FOCAPO 2003 (Eds. I.E. Grossmann and C.M. McDonald), pp.153-165, CACHE (2003).

Sahinidis, N. V., BARON: A General Purpose Global Optimization Software Package, Journal of Global Optimization, 8(2), 201-205, 1996.

Sahinidis, N. V. and M. Tawarmalani, Applications of Global Optimization to Process and Molecular Design, Computers and Chemical Engineering, 24, 2157-2169, 2000.

Sargent, R.W.H., "What is Chemical Engineering?,” CAST Newsletter, 14 (1), pp.9-11 (1991).

Schneider, R. and W. Marquardt, "Information Technology Support in the Chemical Process Design Life Cycle," Chem. Engng Sci. 57 (2002), Issue 10, 1763-1792.

Seinfeld, J.H. and Spyros N. Pandis, "Atmospheric Chemistry and Physics: From Air Pollution to Climate Change," Wiley (1997). 
Seinfeld, J.H., Clouds and Climate: Unraveling a Key Piece of Global Warming, AIChE Journal, 46, 226-228 (2000).

Shah, N., "Pharmaceutical Supply Chains: Key Issues and Strategies for Optimization," Proceedings FOCAPO 2003 (Eds. I.E. Grossmann and C.M. McDonald), pp.73-85, CACHE (2003).

Shapiro, J., "Challenges of Strategic Supply Chain Planning and Modeling," Proceedings FOCAPO 2003 (Eds. I.E. Grossmann and C.M. McDonald), pp.27-34, CACHE (2003).

Shelley, M. D. and M. M. El-Halwagi, 2000, "Componentless Design of Recovery and Allocation Systems: A Functionality-Based Clustering Approach", Comp. Chem. Eng., 24, 2081-2091

Siirola, J.D, Hauan, S. and Westerberg, A.W. "Toward Agents-Based Process Systems Engineering: Proposed Agent Framework," Submitted to Comp. Chem. Eng., April 2002.

Sikdar, S. and M. M. El-Halwagi, Eds., "Process Design Tools for the Environment", Taylor and Francis (2001), New York

Sinha, M., L.E.K. Achenie and G.M. Ostrovsky, "Environmentally Bening Solvent Design by Global Optimization," Computers and Chemical Engineering, 23, 1381-1394 (1999).

Sinha, M., Ostrovsky, G., and Achenie, L. E. K., " On the Solution of Mixed-Integer Nonlinear Programming Models for Computer Aided Molecular Design," Computers and Chemistry, 26(6), 645-660, 2002.

Silva, B.I., O. Stursberg, B.H. Krogh, and S. Engell, "An Assessment of the Current Status of Algorithmic Approaches to the Verification of Hybrid Systems," Proc. 40th IEEE Conf. on Decision and Control, Orlando (Florida), 2867-2874 (2001).

Skogestad, S., "Self-optimizing control: the missing link between steady-state optimization and control", Comp.Chem.Engng., 24, 569-575 (2000).

Stankiewicz, A. and J. A. Moulin, "Process Intensification: Transforming Chemical Engineering," Chemical Engineering Progress, 96(1), pp.22-34 (2000)

Stefanović, J. and C. C. Pantelides, "Towards Tighter Integration of Molecular Dynamics within Process and Product Design Computations”, AIChE Symposium Series, Vol. 96 No. 323, pp. 236-249, (2000).

Stephanopoulos, G. "Is There a Need for a New Process Systems Engineering," $7^{\text {th }}$ Roger Sargent Lecture, Nov. 30 (2000).

Stephanopoulos, Gregory, "Metabolic Engineering: Perspective of a Chemical Engineer," AIChE J.,48, pp.920926 (2002).

Steffens, M.A., E S Fraga and I D L Bogle , "Synthesis of downstream purification processes using physical properties data," Biotechnology \& Bioengineering, 68, 218-230 (2000).

Subramanian, D., J.F. Pekny, G.V. Reklaitis and G.E. Blau, "Simulation-Optimization Framework for Stochastic Optimization of R\&D Pipeline Management," AIChE Journal 49, 96-112 (2003).

Vaidyaraman, S. and C.D. Maranas, "Optimal Refrigeration Cycle Synthesis and Refrigerant Selection," AIChE Journal 45, 997-1017 (1999).

Vargas-Villamil, F.D. and D.E. Rivera, "Multilayer Optimization and Scheduling Using Model Predictive Control: Application to Reentrant Semiconductor Manufacturing Lines," Computers and Chemical Engineering, 24, pp. 2009-2021 (2000). 
Vecchietti, A. and I.E. Grossmann, "Modeling Issues and Implementation of Language for Disjunctive Programming," Computers and Chemical Engineering, 24, pp.2143-2155 (2000).

Venkatsubramanian, V., "Abnormal Events Management in Complex Process Plants: Challenges and Opportunities in Intelligent Supervisory Control," Proceedings FOCAPO 2003 (Eds. I.E. Grossmann and C.M. McDonald), pp.117-132, CACHE (2003).

Westerberg K.M. and C.A. Floudas, "Dynamics of Peptide Folding : Transition States and Reaction Pathways of Solvated and Unsolvated Tetra-Alanine", Journal of Global Optimization, 15, 261-297 (1999).

Westerberg, A.W., and E. Subrahmanian, "Product Design," Comp. Chem. Engng, Vol. 24 (2-7), 959-966 (2000).

Wilson, S., V. Manousiouthakis, "IDEAS Approach to Process Network Synthesis: Application to Multicomponent MEN," AICHE Journal, 46 (12), 2408-2416, (2000).

Winn, D. And Doherty, M.F., "A New Technique for Predicting the Shape of Solution-Grown Organic Crystals," AIChE Journal, 44, 2501-2514 (1998)

Ydstie, B.E., "New Vistas for Process Control: Integrating Physics and Communication Networks," AIChE J., 48, 422-426 (2002).

Ydstie, B.E. and A.A. Alonso, "Process Systems and Passivity via de Clausius-Planck Inequality," Systems and Control Letters, 30, 253 (1997).

Yeomans, H. and I.E. Grossmann, "A Systematic Modeling Framework of Superstructure Optimization in Process Synthesis," Computers and Chemical Engineering , 23, 709-731 (1999).

Zhao ,J., B. Chen, and J. Shen, "Multidimensional non-orthogonal wavelet-sigmoid basis function neural network for dynamic process fault diagnosis, Computers \& Chemical Engineering,", 23(1)83-92 (1998) 